\title{
Comparison Between DNA Immobilization Techniques on a Redox Polymer Matrix
}

\author{
Vijayalakshmi Velusamy ${ }^{1}$, Khalil Arshak ${ }^{1 *}$, Catherine F. Yang ${ }^{2}$, Lei Yu ${ }^{2}$, Olga Korostynska ${ }^{3}$, \\ Catherine Adley ${ }^{4}$ \\ ${ }^{1}$ Electronic and Computer Engineering Department, University of Limerick, Limerick, Ireland \\ ${ }^{2}$ Department of Chemistry and Biochemistry, Rowan University, Glassboro, USA \\ ${ }^{3}$ School of Physics, Dublin Institute of Technology, Dublin, Ireland \\ ${ }^{4}$ Department of Chemical and Environmental Sciences, University of Limerick, Limerick, Ireland \\ E-mail: viji.subha@ul.ie
}

Received February16, 2011; revised April 2, 2011; accepted April 16, 2011

\begin{abstract}
In this paper we report a label-free detection method of unmodified DNA using polypyrrole as an immobilization matrix by impedance measurement. A probe and a target complementary DNA sequence specific for the bacterial pathogen, Bacillus cereus are used. Impedance measurements are performed without using additional redox probes. The effects of hybridization and non-specific binding are compared when the Probe DNA molecules were immobilized by two different methods: electrochemical adsorption and entrapment.

The probe DNA immobilized using electrochemical adsorption yielded better hybridization signals compared to that immobilized using the entrapment method. Control experiments were also performed to prove the specificity of the biosensor in the presence of non complementary DNA. Negligible unspecific binding with the immobilized probe was observed with the electrochemically adsorbed probe, whereas the entrapped probe responded to the non complementary target. The performance of the DNA sensor was characterized using both cyclic voltammetry and impedance spectroscopy techniques and proved to be effective in terms of specificity of hybridization events.
\end{abstract}

Keywords: Immobilization, Label Free DNA, Polypyrrole

\section{Introduction}

Biomolecules of interest called bioreceptors/biorecognition elements can be generally classified into six different major categories. These categories include antibody /antigen, enzymes, nucleic acids/DNA, cellular structures /cells, biomimetic and bacteriophage (phage). Among other biorecognition elements, DNA target has received considerable attention since each organism has its unique DNA sequences and any self-replicating micro-organism can be easily identified. Biosensors based on DNA as biorecognition element are simple, rapid, and highly specific hence widely used in pathogen detection. In contrast to enzyme or antibodies bioreceptors, nucleic acid recognition layers can be readily synthesized and regenerated. However, there are factors which play key roles in the design of DNA biosensors, 1) The immobilization matrix 2) The method of immobilization and 3) The detection technique.
The choice of suitable substrate/matrix to immobilize the DNA is a significant factor since the immobilized single stranded ss-DNA has to be stable on the attached surface to facilitate the hybridization event. Various materials being used to modify the electrode ( $\mathrm{Au}, \mathrm{Ag}, \mathrm{Pt}$, Glassy Carbon, and Indium tin oxide (ITO)) surface and include carbon nanotubes, conducting polymers, metal nanoparticles, composites of various electroactive materials. Conducting polymers (CPs) are preferred among those materials not only because they can be synthesized easily but also due to their high stability, excellent electrical properties and suitable to immobilize the biomolecules [1,2]. Among the various CPs polyaniline, polythiophene, and polypyrrole are biocompatible [3-8] -however, polypyrrole (PPy) is used mostly in biosensors and immunosensors because of its biocompatibility and the ease of immobilization of various biologically active compounds [9]. To detect bio-analytes at a physiological $\mathrm{pH}$, biosensing materials must be electroactive 
in neutral environments, unlike polyaniline and polythiophene. To overcome this problem, PPy is attractive because it can be more easily deposited from neutral $\mathrm{pH}$ aqueous solutions of pyrrole monomers [10]. Most practical types of PPy have conductivity in the range of 1 $100 \mathrm{~S} / \mathrm{cm}$ [11]. PPy can be prepared by various methods such as chemical polymerization [12-16], electrochemical polymerization [17,18], spreading [19,20], vapour phase polymerization [21], plasma polymerization $[22,23]$. The electrochemical polymerization of pyrrole has been extensively studied as it is simple and reliable procedure which does not need sophisticated laboratory equipments and reagents.

One of the critical factors in biosensor design is the development of immobilization methodology that strongly stabilizes the DNA on the transducer surface. Integration of the DNA with the signal transducer is mostly achieved by immobilizing ss-DNA on the electrode/modified surface. Different mechanisms of immobilization techniques are shown in Figure 1.

Mechanisms of immobilization of a label-free umodified DNA probe on the conducting polymer modified surface can be divided into two major categories: i) Adsorption and ii) Entrapment.

While immobilization matrix and method are important in DNA sensor design, the choice of a suitable detection technique is also of great significance in determination of overall performance of the DNA biosensor, in particular with respect to the immobilization and hybridization efficiency of the DNA. The detection techniques employed in the DNA biosensors can be optical [24-27], electrochemical [28-30] or mass [31,32] based. Depending on the nature of the target, the detection parameters can be drawn from the detection of the specific sequence to confirm the presence of target micro-organisms [33,34], DNA damage [35,36], presence of chemical [37] and biological compounds [38], presence of toxic [39] and genotoxic compounds [40].

In general, compared to the other detection techniques, the electrochemical based detection method is more ad

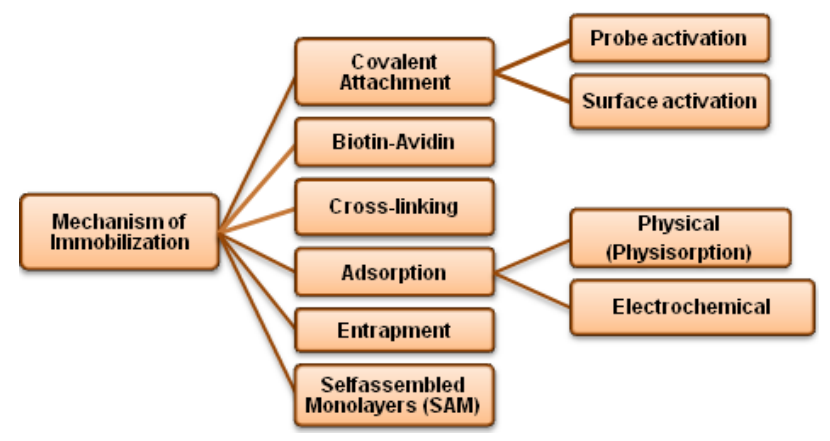

Figure 1. Mechanism of immobilization. vantageous, not only because it is simple, cost effective and reproducible but also due to its suitability for miniaturized real-time handheld use without sacrificing its sensitivity and specificity. In electrochemical DNA biosensors, detection is based on the variation in the electrical properties of the DNA- modified electrode before and after hybridization. It is likely that the change may have resulted from the change of double-layer capacitance, heterogeneous electron transfer resistance, impedance or current. DNA sensors based on electrochemical impedance spectroscopy (EIS) detection is a device that transcribe the changes in interfacial properties between the electrode and the electrolyte induced by DNA hybridization, DNA conformational changes, or DNA damages to an electrical signal [41]. EIS is becoming more and more popular for electrochemical measurements of molecular interactions and is also widely used in a variety of biosensing applications. The principle and applications of EIS to biosensing have been recently summarized in the literature [42]. The method provides unique advantages compared to other electrochemical methods, such as high sensitivity, ease of signal quantification, and ability to separate the surface binding events from the solution impedance [43]. Impedance data are normally recorded in a range of frequencies, using alternating current of small amplitude, thus the EIS is often referred to as AC Impedance. Compared to other electrochemical methods, such as cyclic voltammetry (CV) or differential pulse voltammetry (DPV), known to characterize molecular interactions on the surface of electrodes, AC Impedance is less destructive to the measured biological interactions because it is performed in a very narrow range of small potentials [43]. To characterize the DNA immobilized on the modified electrode surface using EIS, the change in impedimetric response upon hybridization can be measured either in terms of kinetics of electron transfer process by Faradic impedance measurements or in terms of alterations of capacitance and molecular layer organization, originating from biorecognition events, by nonFaradic approach [44].

In this paper, we report the label-free detection of DNA hybridization using Faradic impedance measurements. The PPy modified gold electrode surface was employed to optimize the immobilization of probe DNA molecules and to resist the non specific binding of target DNA molecules. Further, electrochemical adsorption and entrapment methods of immobilization are compared with respect to hybridization with target complementary and non-complementary DNA. Here, the present application is specifically applied to food quality monitoring emphasizing on the detection of the bacterial pathogen, Bacillus cereus. 
Table 1. DNA sequences.

\begin{tabular}{cc}
\hline Function & Sequence \\
\hline Probe (5'-3') & ATC GCC TCG TTG GAT \\
GAC GA \\
Complementary (5'-3') \\
$\begin{array}{c}\text { TCG TCA TCC AAC GAG } \\
\text { GCG AT } \\
\text { (5'-3') }\end{array}$ \\
\hline
\end{tabular}

\section{Experimental}

\subsection{Materials}

Pyrrole and $\mathrm{MgCl}_{2}$ solution were purchased from SigmaAldrich, USA. All the reagents were analytical grade and used without further purification. Specific sequences for the Bacillus cereus were designed in our laboratory [45] and its synthetic form was purchased from Integrated DNA technologies, USA. All stock DNA solutions were prepared using distilled water and a concentration of 1 $\mu \mathrm{g} / \mu \mathrm{l}$ from the stock solution was made using $10 \mathrm{mM}$ Tris-HCl buffer, $\mathrm{pH}$ 7.2. The capture probe and the target probe are 20-mer oligonucleotides and the non complementary probe 21-mer in length. Table 1 shows the sequences of the oligonucleotides used in this work.

\subsection{Instrumentation}

A three-electrode cell comprising - a gold ( $\mathrm{Au}$ ) working electrode (2-mm diameter), a platinum wire counter electrode and a $\mathrm{Ag} / \mathrm{AgCl}$ reference electrode were used. All electrochemical measurements were carried out using Autolab PGSTAT302N (Eco Chemie, The Netherlands) with a Frequency Response Analyser (FRA) module interfaced for impedance measurements.

\subsection{Gold Electrode Surface Modification and Electrochemical Synthesis of Polypyrrole}

The Au electrode surface was polished to mirror finish prior to use sequentially with $1,0.3$, and $0.05 \mu \mathrm{m} \alpha$ $\mathrm{Al}_{2} \mathrm{O}_{3}$ paste, and rigorously rinsed with distilled water following each polish. Prior to surface modification, the bare electrode was scanned in $0.1 \mathrm{M} \mathrm{MgCl}_{2}$ in $10 \mathrm{mM}$ Tris-HCl buffer ( $\mathrm{pH} 7.2)$ between -0.3 and $0.8 \mathrm{~V}$ until a reproducible cyclic voltammogram was obtained. Two different types of methods were employed for immobilization of probe DNA.

The first approach involves incorporation of probe DNA into the polymer matrix during the growth of the
PPy or during the co-deposition of the pyrrole monomer which is known as the entrapment method. The second approach involves the polymerization of the polypyrrole without the presence of DNA and then immobilizing the probe DNA by electrochemical adsorption.

\subsection{Immobilization}

\subsubsection{Immobilization by Entrapment}

Immobilization by co-deposition was achieved using cyclic voltammetry (CV) for 20 cycles over -0.3 to +0.8 $\mathrm{V}$ at a scanning rate of $50 \mathrm{mVs}^{-1}$. The $2 \mathrm{ml}$ solution for immobilization by co-deposition consists of $0.1 \mathrm{M}$ Pyrrole/0.1 $\mathrm{M} \mathrm{MgCl}_{2}$ solution and $1 \mu \mathrm{g}$ of probe DNA.

\subsubsection{Immobilization by Electrochemical Adsorption} First, the electrochemical polymerization of PPy was performed by $\mathrm{CV}$, involved the immersion of an Au disk electrode into a solution of $0.1 \mathrm{M}$ pyrrole containing 0.1 $\mathrm{M} \mathrm{MgCl}_{2}$. A cyclic potential from -0.3 to $0.80 \mathrm{~V}$ (versus $\mathrm{Ag} / \mathrm{AgCl}$ ) for 20 cycles at a scan rate of $50 \mathrm{mVs}^{-1}$ was applied. The Au electrode coated with PPy film was then washed with distilled water and dried under nitrogen gas. The so-prepared PPy-coated electrode was characterized by impedance spectroscopy and CV.

Prior to immobilization, the PPy coated electrode was transferred to a $20 \mathrm{mM} \mathrm{MgCl}_{2}$ and $10 \mathrm{mM}$ Tris- $\mathrm{HCl}$ buffer (pH 7.2) for electrochemical oxidation of the PPy layer at $0.5 \mathrm{~V}$ (versus $\mathrm{Ag} / \mathrm{AgCl}$ ) for $600 \mathrm{~s}$. Immobilization was thereafter achieved by applying a constant potential of $0.8 \mathrm{~V}$ for $600 \mathrm{~s}$ and the $2 \mathrm{ml}$ immobilization solution consisted of $20 \mathrm{mM} \mathrm{MgCl} 2$ in10 mM Tris-HCl buffer ( $\mathrm{pH}$ 7.2) and $1 \mu \mathrm{g}$ of probe DNA. The ss-DNA modified electrode was washed with distilled water to remove loosely adsorbed DNA and dried under nitrogen gas. The ss-DNA/PPy film was later analysed by impedance measurements.

\subsection{Hybridization of the Target DNA}

The hybridization was completed by applying a constant potential of $0.5 \mathrm{~V}$ for $600 \mathrm{~s}$ and the $2 \mathrm{ml}$ hybridization solution consists of $20 \mathrm{mM} \mathrm{MgCl} 2$ in $10 \mathrm{mM}$ Tris-HCl buffer (pH 7.2) and $1 \mu \mathrm{g}$ of complementary DNA strand. The same procedure was repeated with non-complementary DNA as a control experiment.

\subsection{Characterization of the DNA Biosensor}

Both the EIS and CV techniques are used to characterize the performance of the DNA biosensor. All impedance measurements were performed at $0.3 \mathrm{~V}$ bias potential in an analysis buffer consisting of $0.1 \mathrm{M} \mathrm{MgCl}_{2}$ in $10 \mathrm{mM}$ Tris-HCl buffer, with a $\mathrm{pH}$ of 7.2. AC amplitude of 5 $\mathrm{mV}$ was used and the data collected in the frequency 
range of $10 \mathrm{kHz}$ - $100 \mathrm{mHz}$ taking six points per decade. The CV measurements were performed by applying cyclic potential from -0.3 to $0.80 \mathrm{~V}$ (versus $\mathrm{Ag} / \mathrm{AgCl}$ ) for 6 cycles at a scan rate of $50 \mathrm{~m} \cdot \mathrm{Vs}^{-1}$. The analysis buffer for $\mathrm{CV}$ measurements consists of $0.1 \mathrm{M} \mathrm{MgCl}_{2}$ in $10 \mathrm{mM}$ Tris-HCl buffer, with a $\mathrm{pH}$ of 7.2.

\section{Results and Discussion}

\subsection{Polymerization of Pyrrole}

The electrical conduction of PPy is the result of electron movement within delocalized orbitals and positive charge defects known as polarons [46]. In conjugated polymers other than polyacetylene, electrons added or removed from the delocalized $\pi$-bonded backbone initially produce polarons (radical ions coupled to a spatially extended distortion of the bond lengths), which subsequently combine to form dianions or dications (spinless bipolarons), respectively [47]. The applications of conducting polymers in biosensing have been detailed in a recent review [48]. During the electropolymerization of pyrrole, the forming polymer backbone was charged positively. The positive charge is compensated by anions from the electrolyte solution via an incorporation of these anions into the polymer film.

\subsubsection{Cyclic Voltammetry Characteristics of Polymerization of Pyrrole}

The PPy films were deposited on the working Au electrode by scanning the potential between positive $(0.8 \mathrm{~V})$ and negative $(-0.3 \mathrm{~V})$ limits repeatedly for 20 cycles. The anodic oxidation of PPy, where the anions, $\mathrm{Cl}^{-}$from $\mathrm{MgCl}_{2}$ compensate the positive charge of the produced $\mathrm{PPy}^{+}$, enhanced the electrochemical polymerisation of the PPy film and the formation of PPy film was evident from the growth of oxidation current after each cycle. The growth of the PPy can be controlled by varying the

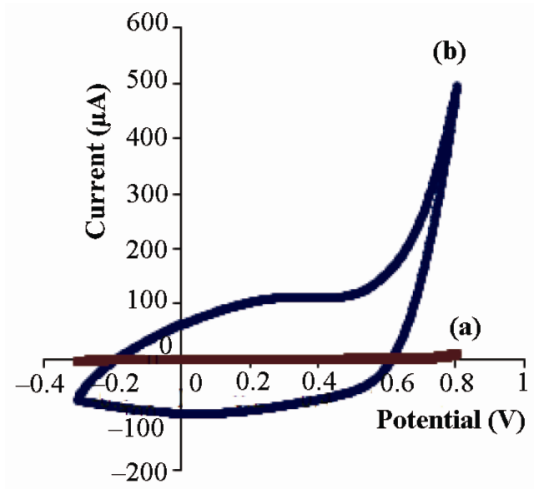

Figure 2. Cyclic voltammograms before (a) and after polymerization process (b). applied positive potential, scan rate, number of scans and also the concentration of monomer/electrolyte ratio. Figure 2 shows the cyclic voltammogram for the PPy film prepared by electrochemical polymerization on $\mathrm{Au}$ electrode. After the bare Au electrode was modified with PPy film, the oxidation current increased significantly. The increase in oxidation current provides the evidence to demonstrate the existence of PPy, which is later confirmed by using EIS.

\subsubsection{Impedance Characteristics of Polymerization of Pyrrole}

EIS measurements impedance is generally expressed as a complex number, which is the combination of the real component, $Z^{\prime}$ mainly from the Ohmic resistance and the imaginary component, $Z^{\prime \prime}$ from the capacitive reactance. The impedance spectra of the conducting polymer were used to evaluate film conductivity and the charge transport at the PPy film/electrolyte interface. Figure 3 shows the Nyquist diagram for the bare $\mathrm{Au}$ electrode and modified Au electrode (Au/PPy) after polymerization using CV. From the Nyquist plot the impedance (resistance) appears to be substantially larger for the bare Au electrode (Figure 3(a)) since there is no ac-

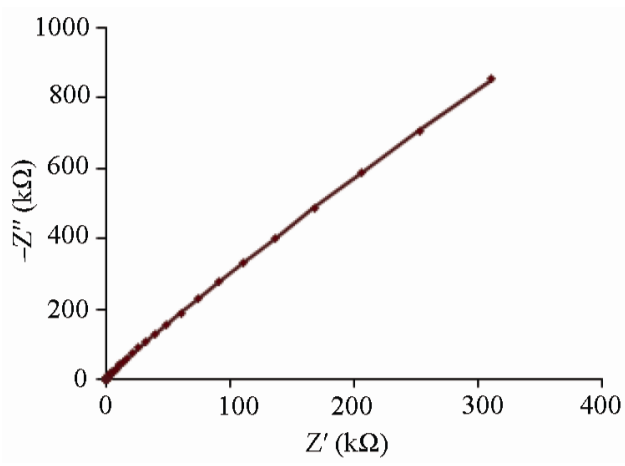

(a)

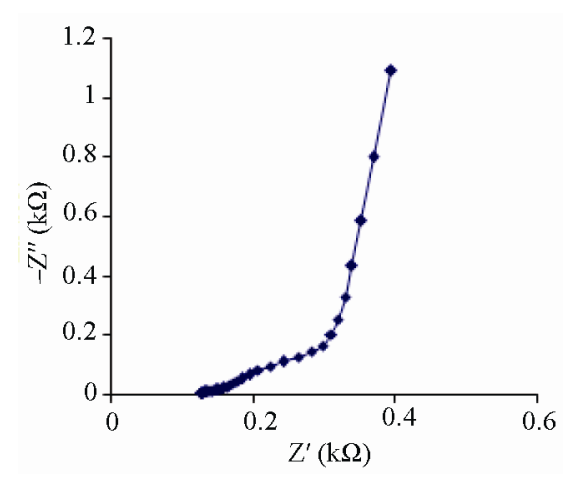

(b)

Figure 3. Nyquist plots before (3a) and after polymerization process (3b) on a gold electrode. 
tive redox species, so no Faradic current. However, the presence of Faradic current was observed in the PPy modified electrode (Figure 3(b)) and the resistance is the charge-transfer resistance of PPy redox reactions on electrode/electrolyte interface.

In general, Faradaic impedance measurements are performed in the presence of a redox couple in solution and rely on changes in the barrier to redox conversion due to the formation of the recognition complex itself or a subsequent complex. The ferri-/ferrocyanide $\left(\mathrm{Fe}(\mathrm{CN})_{6}{ }^{3-/ 4}\right)$ solution is mostly chosen because of its excellent electrochemical reversibility. However, in this case, the presence of an additional redox couple is turned out to be not necessary. Because, conjugated polymers such as polypyrrole, can be oxidised and reduced which is in principle analogous to the redox species.

\subsection{Immobilization and Hybridization of the DNA}

Due to intermolecular force between the DNA and PPy, DNA can firmly bind on the PPy matrix. The underlying principle is that the positively charged PPy can exchange its negatively charged dopant easily with other negatively charged species, including biomolecules [46]. Therefore, PPy provides a unique surface for DNA binding. Due to its delocalized electronic structure, the positively charged sites of PPy are mobile along the chain axis. This allows more flexibility towards the binding of DNA's fixed negative charge sites and hence it provides a higher affinity than surface with fixed positive charges [49]. Hydrogen bonding to phosphate oxygen in the DNA backbone can also enhance the binding to DNA, and PPy could provide such hydrogen bonds through its pyrrole ring nitrogen atom.

\subsubsection{Entrapment}

Entrapment method is typically adopted when conducting polymers are employed as immobilization matrix. In this method the biomolecules are embedded onto the electrode surface during the growth of the conducting polymer and therefore, it creates more stable DNA surface. It is a fast and simple procedure, since it involves co-deposition of pyrrole and ss-DNA together in one step.

\subsubsection{Adsorption}

In electrochemical adsorption forces of attraction between PPy and DNA are due to ion to ion interactions between the negatively charged DNA and the positively charged surface. When a positive potential of $0.8 \mathrm{~V}$ is applied, due to electrostatic attraction, the phosphate group of the DNA molecule binds to the postively charged surface. The electrochemical adsorption has several advantages over physical adsorption or physisorption. In physisorption forces of attraction are due to Van der Waals' forces between the solid surface and the biomolecule. The quantity of biomolecules taken up by the surface depends on several conditions and surface properties including temperature, pressure and the surface roughness.

To detect the hybridization efficiency and to determine the effectiveness of the two immobilization methods, the complementary target DNA was hybridized on the immobilized ss-probe DNA. Both the entrapped and electrostatically adsorbed probes responded to the complementary DNA target. Figure 4 shows the ac impedances measured for the Au/PPy/DNA film before and after the target complementary DNA hybridization and the corresponding Nyquist Plot.

Change in impedance was observed after complementary DNA hybridization for both the entrapped probe (Figure 4(a)) and electrostatically immobilized probe (Figure 4(b)). Figure 4(b) shows the Faradic impedance spectra after the hybridization event, in which the charge transfer resistance increased after the capture DNA probe was immobilized on the PPy film and a further increase in charge transfer resistance from $2 \mathbb{\Omega}$ to $4.46 \mathrm{k} \Omega$ was

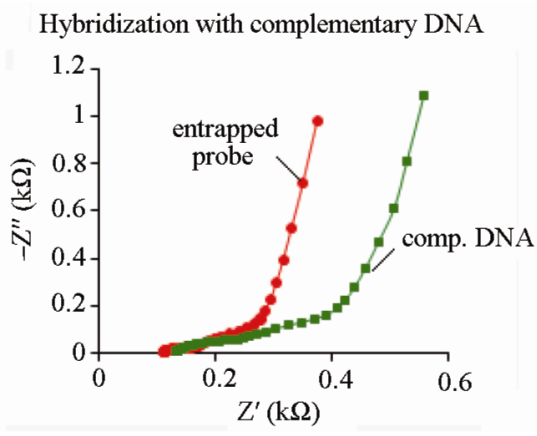

(a)

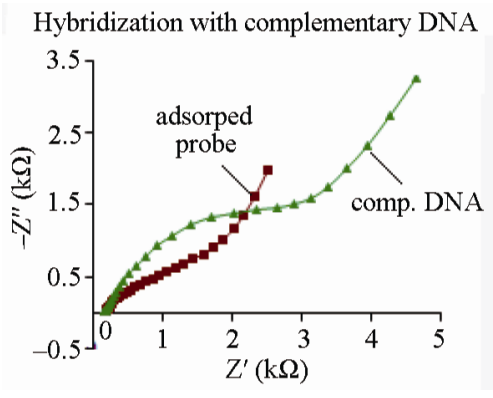

(b)

Figure 4. Nyquist plots afer hybridization with the complementary target DNA (4a) with entrapped probe (4b) with electrostatically adsorbed probe. 
observed after hybridization. The increase in charge transfer resistance is due to presence of the DNA probe at the PPy surface, which blocks the passage of chloride ions at the PPy/solution interface. This should be attributed to the repulsive electrostatic interaction which increased the anionic charge along the backbone of the PPy/ss-DNA and later double the anionic charge by the forming DNA duplex. Accordingly, results indicate that the addition of negative charge to the surface of the PPy/ss-DNA, in the form of complementary oligonucleotide, further blocks the chloride ion exchange which, yields the increase in impedance after hybridization.

\subsection{Specificity of the System}

The specificity of this protocol was investigated by varying the target DNA sequence. A non complementary sequence was used to hybridize with the immobilized capture DNA probe and only negligible unspecific binding was observed with the probe immobilized by electrostatic adsorption (Figure 5(b)). Whereas, the entrapped probe responds to the non-complementary target DNA which showed an effect on the charge transfer resistance (Figure 5(a)). Therefore, the electrostatically immobilized DNA sensor demonstrated has more effectiveness in terms of specificity of hybridization events and to con-

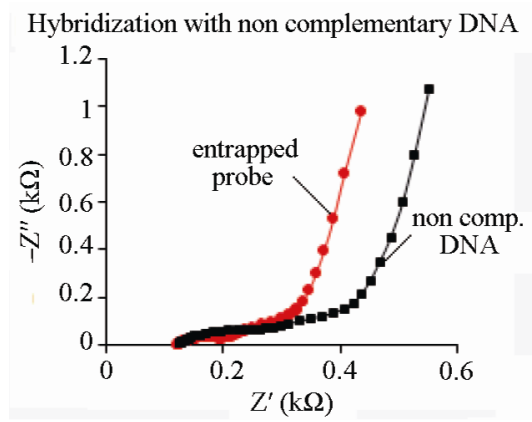

(a)

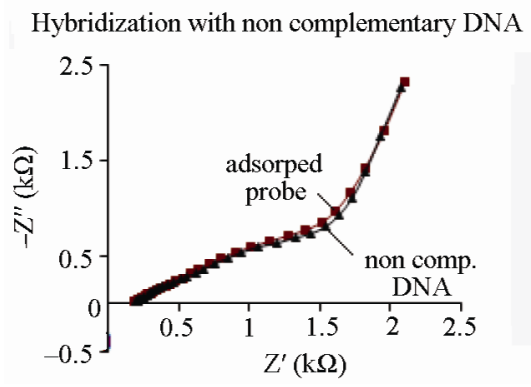

(b)

Figure 5. Nyquist plots afer hybridization with the non complementary target DNA (5a) with entrapped probe (5b) with electrostatically adsorbed probe. firm this, the hybridization events were also characterized using cyclic voltammetry. From the cyclic voltammograms results shown in Figure 6(a), a decrease in oxidation current was observed after hybridization with complementary target DNA and only a negligible effect in the change in oxidation current was observed with non complementary DNA (Figure 6(b)).

Whatever the method of immobilization, the key performance criterion of a DNA biosensor lays in its efficiency of hybridization. In theory, this should depend on i) the surface characteristics, ii) the surface coverage of probe molecules, iii) probe orientation of the surface, and iv) factors controlling the transport of target molecules to the surface [50]. Although, entrapped probe leads to a more stable immobilization by containing the oligonucleotides within the PPy bulk, it invariably leads to some extend of steric and kinetic barriers to the hybridization of a macromolecule. In addition, the oligonucleotide probe can be oxidatively damaged by radical cations formed during pyrrole polymerization, leading to its par-

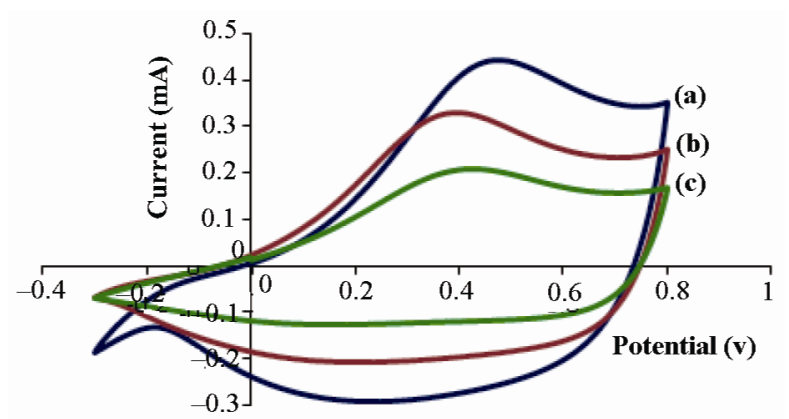

(a)

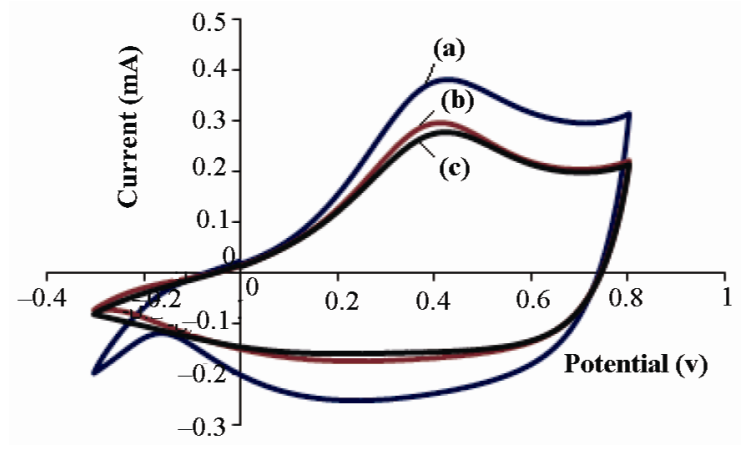

(b)

Figure 6. Characterization of the hybridization events of the complementary (6a) and non complementary target DNA (6b) with the electrostatically adsorbed probe. Cyclic Voltammograms (a) of the polymerized gold electrode -Au/PPy, (b) after immobilization of electrostaically adsorbed probe-Au/PPy/ssDNA (c) after hybridization with complementary DNA target -Au/PPy/dsDNA and (d) after hybridization with non complementary DNA. 
tial degradation [51].

In electrochemical adsorption, by application of a potential to the electrode, the delocalized positive charge of the oxidized PPy electrostatically attracts the negatively charged phosphate groups of the DNA. Also, controlled adsorption of DNA onto the PPy surface can be obtained since the positively charged PPy substrate exerts electrostatic attraction on the DNA molecules. The quantity and strength of adsorption depends on the nature of the anion dopant (electrolyte, in this case $\mathrm{MgCl}_{2}$ ), type and the ionic strength of the buffer used, solution $\mathrm{pH}$, and on the DNA itself. While the DNA surface coverage can be controlled, the DNA conformation and orientation on the surface is difficult to modulate. Studies [52-54] suggest that electrostatically driven DNA adsorption results in orientation of the molecules parallel to, rather than perpendicular to the surface, with base pairing sites exposed to the liquid medium. However, the results show that the orientation is appropriate to target DNA hybridization and does not limit specificity of the biosensor.

\section{Conclusions}

Electrochemically assisted adsorption of DNA on the PPy modified electrode surface leads to more active and functional DNA layers. This method takes advantage over the entrapment method. Therefore, the DNA-PPy surface interaction is stronger and more stable when a potential is applied during adsorption. Moreover, the measurements performed in an inert electrolyte solution resulted in much higher impedance due to the presence of redox polymer and were reproducible. Therefore, the application of redox conductive polymer such as PPy as an immobilization matrix is an attractive approach in which the presence of external redox probe or active species can be totally eliminated. A further study of nucleic acid interaction on transducer interfaces and the investigation of conformation of DNA on the electrode surface can generate the insights on the design surfaces for more effective hybridization.

\section{Acknowledgements}

This project is funded by Science Foundation Ireland (SFI) Research Frontiers Programme, ID no: 07RPFENEF500. The presented research work was co funded by SFI-Short Term Travel Fellowship award.

\section{References}

[1] M. V. Murugendrappa and M. V. N. Ambika Prasad, "Dielectric Spectroscopy of Polypyrrole-[Gamma]-Fe2O3 Composites," Materials Research Bulletin, Vol. 41, No. 7, 2006, pp. 1364-1369. doi:10.1016/j.materresbull.2005.12.011

[2] B. D. Malhotra, A. Chaubey and S. P. Singh, "Prospects of Conducting Polymers in Biosensors," Analytica Chimica Acta, Vol. 578, No. 1, 2006, pp. 59-74. doi:10.1016/j.aca.2006.04.055

[3] R. J. Geise, J. M.Adams, N. J. Barone and A. M. Yacynych, "Electropolymerized Films to Prevent Interferences and Electrode Fouling in Biosensors," Biosensors \& Bioelectronics, Vol. 6, No. 2, 1991, pp. 151-160. doi:10.1016/0956-5663(91)87039-E

[4] N. J. Trujillo, M. C. Barr, S. G. Im and K. K. Gleason, "Oxidative Chemical Vapor Deposition (oCVD) of Patterned and Functional Grafted Conducting Polymer Nanostructures,” Journal of Materials Chemistry, Vol. 20, No. 19, pp. 3968-3972. doi:10.1039/b925736e

[5] S. Liu, J. Q. Wang, D. Zhang, P. L. Zhang, J. F. Ou, B. Liu and S. R. Yang, "Investigation on Cell Biocompatible Behaviors of Polyaniline Film Fabricated via Electroless Surface Polymerization,” Applied Surface Science, Vol. 256, No. 11, pp. 3427-3431. doi:10.1016/j.apsusc.2009.12.046

[6] F. Wei, W. Liao, Z. Xu, Y. Yang, D. T. Wong and C. M. Ho, "Bio/Abiotic Interface Constructed from Nanoscale DNA Dendrimer and Conducting Polymer for Ultrasensitive Biomolecular Diagnosis”, Small, Vol. 5, No. 15, 2009, pp. 1784-1790. doi:10.1002/smll.200900369

[7] H. S. Kim, H. L. Hobbs, L. Wang, M. J. Rutten and C. C. Wamser, "Biocompatible Composites of Polyaniline Nanofibers and Collagen," Synthetic Metals, Vol. 159, No. 13, 2009, pp. 1313-1318. doi:10.1016/j.synthmet.2009.02.036

[8] N. K. E. Guimard, J. L.Sessler and C. E. Schmidt, “Toward a Biocompatible and Biodegradable Copolymer Incorporating Electroactive Oligothiophene Units," Macromolecules, Vol. 42, No. 2, 2009, pp. 502-511. doi:10.1021/ma8019859

[9] A. Ramanaviciene and A. Ramanavicius, "Application of Polypyrrole for the Creation of Immunosensors," Critical Reviews in Analytical Chemistry, Vol. 32, No. 3, 2002, pp. 245-252. doi:10.1080/10408340290765542

[10] A. Ramanavicius, A. Ramanaviciene and A. Malinauskas, "Electrochemical Sensors Based on Conducting Polymer-Polypyrrole,” Electrochimica Acta, Vol. 51, No. 27, 2006, pp. 6025-6037. doi:10.1016/j.electacta.2005.11.052

[11] M. V. Murugendrappa and M. Prasad, "Chemical Synthesis, Characterization, and Direct-Current Conductivity Studies of Polypyrrole/Gamma-Fe2O3 Composites," Journal of Applied Polymer Science, Vol. 103, No. 5, 2007, pp. 2797-2801. doi:10.1002/app.23868

[12] S. Uzun and M. Can, "Oxidizing Effect on Chemical Polymerization of Pyrrole Monomer in Anhydrous Media,” Asian Journal of Chemistry, Vol. 22, No. 2, 2010, pp. 1321-1330.

[13] S. Cavallaro, A. Colligiani and G. Cum, “Oxidative Chemical Polymerization of Pyrrole-Calorimetric and Kinetic Measurements,"Journal of Thermal Analysis and Calorimetry, Vol. 38, No. 12, 1992, pp. 2649-2655. doi:10.1007/bf01979741 
[14] J. Duchet, R. Legras and S. Demoustier-Champagne, "Chemical Synthesis of Polypyrrole: Structure-Properties Relationship,” Synthetic Metals, Vol. 98, No. 2, 1998, pp. 113-122. doi:10.1016/S0379-6779(98)00180-5

[15] P. Dutta and S. K Mandal, "Charge Transport in Chemically Synthesized, DNA-Doped Polypyrrole,” Journal of Physics D-Applied Physics, Vol. 37, No. 20, 2004, pp. 2908-2913. doi:10.1088/0022-3727/37/20/019

[16] A. K. Sharma, J. H. Kim and Y. S. Lee, “An Efficient Synthesis of Polypyrrole/Carbon Fiber Composite Nanothin Films," International Journal of Electrochemical Science, Vol. 4, No. 11, 2009, pp. 1560-1567.

[17] S. Stankovic, R. Stankovic, M. Ristic, O. Pavlovic and M. Vojnovic, "Some Aspects of the Electrochemical Synthesis of Polypyrrole," Reactive \& Functional Polymers, Vol. 35, No. 3, 1997, pp. 145-151. doi:10.1016/S1381-5148(97)00090-4

[18] K. Ghanbari, S. Z. Bathaie and M.F. Mousavi, "ElectroChemically Fabricated Polypyrrole Nanofiber-Modified Electrode as a New Electrochemical DNA Biosensor," Biosensors \& Bioelectronics, Vol. 23, No. 12, 2008, pp. 1825-1831. doi:10.1016/j.bios.2008.02.029

[19] O. Fichet, F. Tran-Van, D. Teyssie and C. Chevrot, "Interfacial Polymerization of a 3, 4-Ethylenedioxythiophene Derivative Using Langmuir-Blodgett Technique. Spectroscopic and Electrochemical Characterizations," Thin Solid Films, Vol. 411, No. 2, 2002, pp. 280-288. doi:10.1016/S0040-6090(02)00271-7

[20] M. P. Srinivasan and F. J. Jing, "Composite LangmuirBlodgett Films Containing Polypyrrole and Polyimide,” Thin Solid Films, Vol. 327-329, 1998, pp. 127-130. doi:10.1016/S0040-6090(98)00613-0

[21] S. M. Shang, X. M. Yang, X. M. Tao and S. S. Lam, "Vapor-Phase Polymerization of Pyrrole on Flexible Substrate at Low Temperature and its Application in Heat Generation,” Polymer International, Vol. 59, No. 2, 2010, pp. 204-211.

[22] H. Goktas, F. G. Ince, A. Iscan, I. Yildiz, M. Kurt and I. Kaya, "The Molecular Structure of Plasma Polymerized Thiophene and Pyrrole Thin Films Produced by Double Discharge Technique," Synthetic Metals, Vol. 159, No. 19-20, 2009, pp. 2001-2008. doi:10.1016/j.synthmet.2009.07.003

[23] Z. Zhang, P. Liang, X. Zheng, D. Peng, F. Yan, R. Zhao and C.-L. Feng, "DNA Immobilization/Hybridization on Plasma-Polymerized Pyrrole,” Biomacromolecules, Vol. 9, No. 6, 2008, pp. 1613-1617. doi:10.1021/bm800111a

[24] Z. B. Bahsi, A. Buyukaksoy, S. M. Olmezcan, F. Simsek, M. H. Aslan and A. Y.Oral, "A Novel Label-Free Optical Biosensor Using Synthetic Oligonucleotides from E. coli O157:H7: Elementary Sensitivity Tests,” Sensors, Vol. 9, No. 6, 2009, pp. 4890-4900. doi:10.3390/s90604890

[25] J. Liu, and Y. Lu, "Colorimetric and Fluorescent Biosensors Based on Directed Assembly of Nanomaterials with Functional DNA,” Integrated Analytical Systems, Springer, New York, 2009, pp. 155-178. doi:10.1007/978-0-387-73711-9_6
[26] A. K. Singh, D. Senapati, S. G. Wang, J. Griffin, A. Neely, P. Candice, K. M. Naylor, B. Varisli, J. R. Kalluri and P. C. Ray, "Gold Nanorod Based Selective Identification of Escherichia coli Bacteria Using Two-Photon Rayleigh Scattering Spectroscopy,” Acs Nano, Vol. 3, No. 7, 2009, pp. 1906-1912. doi:10.1021/nn9005494

[27] P. S. Petrou, S. E. Kakabakos and K. Misiakos, "Silicon Optocouplers for Biosensing," International Journal of Nanotechnology, Vol. 6, No. 1-2, 2009, pp. 4-17.

[28] S. J. P. Canete, W. W. Yang and R. Y. Lai, "Folding-Based Electrochemical DNA Sensor Fabricated by ‘Click' Chemistry,” Chemical Communications, No. 32, 2009, pp. 4835-4837.

[29] J. Jiang, D. Jiang, Y. Li, J. Wang and K. L. P. Sung, "Polypyrrole-Based Genolelectronics: Electrochemical DNA Biosensors,” Science \& Technology Review, No. 11, 2009, pp. 93-101.

[30] V. Velusamy, K. Arshak, O. Korostynska, K. Oliwa and C. Adley, "Design of a Real Time Biorecognition System to Detect Foodborne Pathogens-DNA Biosensor," in SAS 2009. New Orleans, USA, 2009, pp. 38-41.

[31] P. I. Reyes, Z. Zhang, H. H. Chen, Z. Q. Duan, J. Zhong, G. Saraf, Y. C. Lu, O. Taratula, E. Galoppini and N. N. Boustany, “A ZnO Nanostructure-Based Quartz Crystal Microbalance Device for Biochemical Sensing," IEEE Sensors Journal, Vol. 9, No. 10, 2009, pp. 1302-1307. doi:10.1109/JSEN.2009.2030250

[32] A. Tsortos, G. Papadakis and E. Gizeli, "Shear Acoustic Wave Biosensor for Detecting DNA Intrinsic Viscosity and Conformation: A study with QCM-D,” Biosensors \& Bioelectronics, Vol. 24, No. 4, 2008, pp. 836-841. doi:10.1016/j.bios.2008.07.006

[33] J. Wang, G. Rivas, C. Parrado, X. H. Cai and M. N. Flair, "Electrochemical Biosensor for Detecting DNA Sequences from the Pathogenic Protozoan Cryptosporidium parvum,” Talanta, Vol. 44, No. 11, 1997, pp. 2003-2010. doi:10.1016/S0039-9140(96)02191-1

[34] D. Zhang and E. C. Alocilja, "Characterization of Nanoporous Silicon-Based DNA Biosensor for the Detection of Salmonella Enteritidis,” IEEE Sensors Journal, Vol. 8, No. 5-6, 2008, pp. 775-780. doi:10.1109/JSEN.2008.923037

[35] V. Vyskocil, J. Labuda and J. Barek, "Voltammetric Detection of Damage to DNA Caused by Nitro Derivatives of Fluorene Using an Electrochemical DNA Biosensor," Analytical and Bioanalytical Chemistry, Vol. 397, No. 1, pp. 233-241. doi:10.1007/s00216-010-3517-y

[36] A. M. Nowicka, A. Kowalczyk, Z. Stojek and M. Hepel, "Nanogravimetric and Voltammetric DNA-Hybridization Biosensors for Studies of DNA Damage by Common Toxicants and Pollutants,” Biophysical Chemistry, Vol. 146, No. 1, pp. 42-53. doi:10.1016/j.bpc.2009.10.003

[37] S. L. Yang, B. Y. Xia, X. D. Zeng, S. L. Luo, W. Z. Wei and X. Y. Liu, "Fabrication of DNA functionalized carbon nanotubes/ $\mathrm{Cu}^{2+}$ complex by one-step electrodeposition and its sensitive determination of nitrite," Analytica Chimica Acta, Vol. 667, No. 1-2, pp. 57-62. doi:10.1016/j.aca.2010.03.063 
[38] H. J. Qiu, Y. L. Sun, X. R. Huang and Y. B. Qu, "A Sensitive Nanoporous Gold-Based Electrochemical Aptasensor for Thrombin Detection," Colloids and Surfaces B-Biointerfaces, Vol. 79, No. 1, pp. 304-308. doi:10.1016/j.colsurfb.2010.04.017

[39] A. M. Tencaliec, S. Laschi, V. Magearu and M. Mascini, "A Comparison Study between a Disposable Electrochemical DNA Biosensor and a Vibrio Fischeri-Based Luminescent Sensor for the Detection of Toxicants in Water Samples," Talanta, Vol. 69, No. 2, 2006, pp. 365-369. doi:10.1016/j.talanta.2005.09.042

[40] G. Bagni, T. Baussant, G. Jonsson, J. Barsiene and M. Mascini, "Electrochemical Device for the Rapid Detection of Genotoxic Compounds in Fish Bile Samples," Analytical Letters, Vol. 38, No. 15, 2005, pp. 2639-2652. doi:10.1080/00032710500371105

[41] J. Y. Park and S. M.Park, "DNA Hybridization Sensors Based on Electrochemical Impedance Spectroscopy as a Detection Tool," Sensors, Vol. 9, No. 12, 2009, pp. 9513-9532. doi:10.3390/s91209513

[42] V. Velusamy, K. Arshak, O. Korostynska, K. Oliwa and C. Adley, "An Overview of Foodborne Pathogen Detection: In the Perspective of Biosensors," Biotechnology Advances, Vol. 28, No. 2, 2010, pp. 232-254. doi:10.1016/j.biotechadv.2009.12.004

[43] A. Bogomolova, E. Komarova, K. Reber, T. Gerasimov, O. Yavuz, S. Bhatt and M. Aldissi, "Challenges of Electrochemical Impedance Spectroscopy in Protein Biosensing," Analytical Chemistry, Vol. 81, No. 10, 2009, pp. 3944-3949. doi:10.1021/ac9002358

[44] C. Gautier, C. Esnault, C. Cougnon, J.-F. Pilard, N. Casse, and B. Chénais, "Hybridization-induced interfacial changes detected by non-Faradaic impedimetric measurements compared to Faradaic approach," Journal of Electroanalytical Chemistry, Vol. 610, No. 2, 2007, pp. 227-233. doi:10.1016/j.jelechem.2007.07.013

[45] C. Adley, K. Arshak, C. Molnar, K. Oliwa and V. Velusamy, "Design of Specific DNA Primers to Detect the Bacillus Cereus Group Species,” Sensors Applications Symposium, New Orleans, USA, 2009, pp. 236-239. doi: 10.1109/SAS.2009.4801807

[46] F. Devreux, F. Genoud, M. Nechtschein and B. Villeret,
"Electron-spin-resonance investigation of polarons and bipolarons in conducting polymers-the case of polypyrrole," Synthetic Metals, Vol. 18, No. 1-3, 1987, pp. 89-94. doi:10.1016/0379-6779(87)90859-9

[47] A. O. Patil, A. J. Heeger and F. Wudl, "Optical-Properties of Conducting Polymers,” Chemical Reviews, Vol. 88, No. 1, 1988, pp. 183-200. doi:10.1021/cr00083a009

[48] K. Arshak, V. Velusamy, O. Korostynska, K. Oliwa-Stasiak and C. Adley, "Conducting Polymers and Their Applications to Biosensors: Emphasizing on Foodborne Pathogen Detection,” IEEE Sensors Journal, Vol. 9, No. 12, 2009, pp. 1942-1951. doi:10.1109/JSEN.2009.2032052

[49] D. S. Minehan, K. A. Marx and S. K. Tripathy, "DNA Binding to Electropolymerized Polypyrrole: The Dependence on Film Characteristics," Journal of macromolecular science. Pure and applied chemistry, Vol. 38 2001, pp. 1245-1258. doi:10.1081/MA-100108381

[50] K. L.Hanson, l. Filipponi and D. V. Nicolau, "Biomolecules and cells on surfaces: Fundamental concepts," Uwe R. Müller and Dan V. Nicolau, Editors, Microarray Technology: Fundamentals, Fabrication and Applications, Springer Verlag, 2004, pp. 23-44.

[51] L. A. Thompson, J. Kowalik, M. Josowicz and J. Janata, "Label-Free DNA Hybridization Probe Based on a Conducting Polymer," Journal of the American Chemical Society, Vol. 125, No. 2, 2002, pp. 324-325. doi:10.1021/ja027929z

[52] V. Chan, D. J. Graves, P. Fortina and S. E. McKenzie, "Adsorption and Surface Diffusion of DNA Oligonucleotides at Liquid/Solid Interfaces,” Langmuir, Vol. 13, No. 2, 1997, pp. 320-329. doi:10.1021/la960670b

[53] V. Chan, S. E. McKenzie, S. Surrey, P. Fortina and D. J. Graves, "Effect of Hydrophobicity and Electrostatics on Adsorption and Surface Diffusion of DNA Oligonucleotides at Liquid/Solid Interfaces,” Journal of Colloid and Interface Science, Vol. 203, No. 1, 1998, pp. 197-207. doi:10.1006/jcis.1998.5495

[54] A. M. Oliveira Brett, and A.-M. Chiorcea, "Atomic Force Microscopy of DNA Immobilized onto a Highly Oriented Pyrolytic Graphite Electrode Surface,” Langmuir, Vol. 19, No. 9, 2003, pp. 3830-3839. doi:10.1021/la027047d 